\title{
Evaluation of Nutrition Education Program among Egyptian Adolescents School Children (11-14 years old)
}

\author{
Safaa E. Tawfik, ${ }^{*}$, Hanan S. Ez elarab ${ }^{* *}$ Wafaa A. Fahmy ${ }^{*}$ And Fatma A. Meky ${ }^{* *}$ \\ *National Nutrition Institute - Cairo - Egypt \\ *** Department of community Medicine- Faculty of Medicine- Ain Shams University
}

\begin{abstract}
:
Background: Consequences of malnutrition can be prevented by starting healthy lifestyle habits among school children as early as possible. School based interventions may play a great role in promoting and enhancino.

$\mathrm{g}$ healthy habilts among them. Yet, there is a lack, of published data about the extent of knowledge about nutrition and physical activity among Egyptian school children. Objective: The main objectives of this study were to evaluate the baseline information of targeted school children regarding nutrtion knowledge, and to assess changes in nutrition knowledge before and after application of nutrition education program. Methods: Prepost study was carried out by a team of National Nutrition Institute in 2011. Four preparatory govermental schools were selected using purposive non probability sampling. Sample size was 320 students. Data were collected using a self adminstered questionnaire that was completed at pre and post intervention. The intervention program was run along 5 weeks and included five sessions encompassing several topics related to nutrition. Several teaching strategies and activities were used during the intervention such as small group discusions, group works, nutrition exhibition and others. Results: Only 3.3 percent of studied sample scored fair (50-75\% of answers were correct ) in pre intervention (all sessions combined), however the percentage increased to $50.6 \%$ after application of the intervention $(\mathrm{P}<0.0001)$. The percentages of overweight and obese in the studied sample were $17.0 \%$ and $10.9 \%$ respectively. There was a significant increase in mean score of knowledge post intervention compared to pre intervention in each session and in all sessions combined in both male and female students.

Conclusion: this study has shown that a school nutrition intervention program could have positive effects on adolescent's school children. In addition, the utilization of different teaching and learning strategies such as group discussion on nutrition topics, demonstrations, nutrition contents, games and other methods may enhance the learning process of the students and increase their awarness towards healthy nutritional behavior.
\end{abstract}

Key words: Adolescents, nutrition knowledge, school intervention

\section{Introduction:}

Nutritional status is a powerful determinant of numerous health, developmental and educational outcomes among youth. In addition to affecting physical growth and maturation, it influences a young person's attention span, learning capacity and ability to fully engage in educational experiences. Worldwide, childhood obesity is a challenging 
problem that affects not only developed countries but also middle and low income countries ${ }^{(1)}$. However, in the latter countries, under nutrition is still a burden in addition to over nutrition and obesity ${ }^{(2)}$. Acoording to WHO (2004) (3), $10 \%$ of school-aged children, between five and 17 years old, are estimated to be overweight or obese worldwide, and the situation is getting worse. In Egypt, according to DHS data in 2008, the rates of overweight and obesity are increasing with $11 \%$ of children aged 10-19 years old were overweight and the risk of obesity among those can reach to up to $15 \%$ in males and $19 \%$ in females ${ }^{(2)}$. Childhood obesity has both immediate and long term effects on health and well being; among the immediate effects, obese youth are more likely to carry the risk factors of cardiovascular disease and other chronic diseases and psychological problems such as poor self esteem. Regarding the long term effects, obese youth are likely to be obese as adults and are therefore more at risk for adult chronic health problems ${ }^{(4,5)}$.

Healthy lifestyle habits, including healthy eating and physical activity can lower the risk of becoming obese and developing related diseases. Schools are regarded as an excellent setting to promote lifelong healthy behaviors through nutritional educational programs. Schools are considered the next most important influencer in childhood development after parents. Some of the reasons, schools are so important in promoting healthy lifestyle habits are reported by Pietsch, $2009^{(5)}$; and earlier by WHO, $1998^{(6)}$, all children and youth can be reached, one to two meals are consumed by students at school, role models of teachers, children attend school for about nine months of years. Furthermore, schoolbased interventions can improve eating behaviours ofyouth, it is therefore important that the school environment enable and reinforce healthful eating and health behaviors through behavioralfocused classroom instruction.

According to WHO (1998) ${ }^{(6)}$, "nutrition interventions are policies, services, learning experiences and other actions implemented by schools, individuals or groups". Several studies from different parts of the world have shown that nutrition education programs classrooms based are effective and efficient to influence the eating behavior of children ${ }^{(7-13)}$. The goal of nutrition education is to motivate participants to eat a healthy diet. Children are a very important audience for nutrition education because a healthy diet is essential for their normal growth and development, and because children are establishing food patterns that carry into adulthood ${ }^{(6)}$.

Yet, there is a lack, of published data about the extent of knowledge about nutrition and physical activity among Egyptian school children thus, the main objectives of this study were to evaluate the base line information of targeted school children regarding nutrtion knowledge, identify the prevalence of obesity among them and to assess changes in nutrition knowledge before and after application of nutrition education program.

Subjects and Methods:

\section{Study design:}

Pre-post intervention study was carried out by a trained team from National Nutrition Institute, in the academic year 2011-2012.

Population and sampling method: No. 4 October 2015 
Four middle preparatory govermental schools (One for boys( Shobramint school ), one for girls (Orman school) and the other two mixed (Mohamadia school and Atef Sadky school), were selected from the school list of UNESCO associated schools in Egypt using purposive non probability sampling. Two of the selected schools were located in the urban area and semiurban areas of Cairo Governorate and the other schools located in the semiurban and rural areas of Giza Governorate.Sample size was 330 , however, the final sample who completed the whole intervention program was droped to 247 students.

\section{Methods of data collection and tools:}

Data were collected using a validated and pretested questionnaire developed by Nutritionist experts from National Nutrition Institute. Before conduction of the study, the questionnaire was piloted on students from one of the selected schools to ensure validity of the questionnaire and the necessary changes were done (Those students were not included in the study).

The questionnaire included questions about gender, school type and 41 questions measuring the nutrition knowledge of students. The nutrition knowledge were divided into five parts; first part measuring knowledge of students about health benefits and caloric content of essential nutrients (13 questions), second part including knowledge about food's recommended portions to eat from each food group ,finding examples of food from each group, estimation of serving size of different food in each group (11 questions), third part including knowledge about recommended calories for adult and recommended calories for breakfast, factors enhancing and hindering Iron absorption, healthy snaks(4 questions), Forth part including knowledge about age of maximum bone density, food rich in calcuim, calcium content of cup of a milk, calcium absorption, sports for bone building ( 5 questions) and last part including knowledge about different types of physical exercises and suitable time for warming and cooling for physical exercises (8 questions). All questions were in the form of multiple choice questions. Knowledge score was calculated by summing all correct answers (1 mark was given for correct answer and zero mark for false answer) for each session (Total score mark for each educational session were $13,11,4,5,8$ respectively). and for the whole workshop (0-41). The total kwolodge score was categorized into good when more than $75 \%$ of answers were correct, fair when $50 \%$ to $75 \%$ of the answers correect and poor when less than $50 \%$ of answers were correct.

Weight and height were measured for all students then body mass index (BMI) was calculated as $\mathrm{kg} / \mathrm{m} 2$, categorization of body weight was done according to CDC growth chart. The categories were "1" for underweight ( 5 th percentile), " 2 " for normal weight, (5th-84th percentile), "3" for overweight (85th94th percentile), and " 4 " for obese (_95th percentile).

\section{Intervention program:}

Intervention program was held as a training workshop and students were divided into groups of 20 to allow more interaction and active participation of students. The duration of intervention program was 5 weeks. This workshop was composed of five sessions encompassing the topics mentioned in

$\begin{array}{lll}\text { Vol. } 33 & \text { No. } 4 & \text { October } 2015\end{array}$


knowledge questionnaire in brief were Essential nutrients, Food Groups, Dietary recommendations, Milk and bone health and Physical activity and health. One session were conducted every week for each school and each session last for an hour. Different teaching strategies and activities were included in each session such as classroom-based teaching, small group discussions, group works, demonstrations, nutrition exhibitions, presentations, workbook assignments, and display of nutrition messages on schools' bulletin boards and school canteens. Also a manual was produced. Competitive activities were held between the students .Many art educational drawings by students whether wall paper, posters, wood or fabric, or cloth painting which all were exhibited on the final ceremony of the project. Gifts such as T-shirts and caps were provided for students.

Immediately after completing the intervention, students who attended the five sessions were subjected to post test (same questionnaire as pretest).Trained researchers provided assistance and clarification to the students during the completion of the questionnaire when needed.

\section{Ethical consideration:}

Ethical approval and logistical support was carried out by Egyptian National commission of UNESCO.

\section{Statistical analysis:}

Data were analyzed using the Statistical Package for the Social Sciences (version 16.0, SPSS, Inc, Chicago, IL). Descriptive statistics are presented as counts, percentages, and means \pm standard deviations. Student's t test was by gender Paired " $\mathrm{t}$ " test was used to examine the means of nutrition knowledge scores before and after intervention. Analysis of variance (ANOVA) was used to analyze means of nutrition knowledge scores by type of school. Differences with $\mathrm{P}<0.05$ were considered significant.

\section{Results}

The total number of students were 330 students, almost one quarter of the sample (80 out of 330) was lost in the follow up, so the final studied sample who completed both pre and post tests in the current study was 247 including 148 $(59.9 \%)$ males and 99 (40.1\%) females. Main reasons for loss include incomplete post intervention and student absences on data collection days. Total knowledge scores related to nutrition of studied sample before application of education intervention program were shown in

Table 1. Mean and standard deviation of total score of nutrition knowledge (all sessions combined) for the studied sample was $13.5 \pm 4.2$. The mean of total score of nutrition knowledge in females (14.3) was significantly higher than that in males (13.0) $(\mathrm{P}=0.02)$. Moreover, location of school was important factor when it was analyzed according to gender. In males, mean of total score of nutrition knowledge of students from rural school (10.9) was significantly lower compared to scores of students from schools of urban area in Cairo governorate (13.6) or semiurban area in Giza Governorate (13.8) $(\mathrm{P}=0.004)$. However, in females mean of total score of nutrition knowledge of students from semiurban area in Cairo (15.9) was significantly higher than scores of students in Giza governorate both 
semiurban (13.4) and rural areas (13.1) $(\mathrm{P}=0.002)$.

Figure 1 showed the percentage of students according to weight status by gender. This figure showed that the percentages of overweight and obese in the studied sample were $17.0 \%$ and $10.9 \%$ respectively. The prevalence of obesity among female students $(17.2 \%)$ was significantly higher $(\mathrm{p}$ value $=0.01)$ than the prevalence of obesity among male students $(6.8 \%)$.

Table 2 showed scores of nutrition knowledge pre and post intervention by gender. Pre intervention, the percentages of students who scored fair $(50-75 \%$ of answers were correct ) were $13.8 \%$ in session 1(knowledge about health benefits of essential nutrients); $16.6 \%$ in session 2 (knowledge about food groups in food pyramid); $18.2 \%$ in session 3 (knowledge about dietary guidelines ), 9.3\% in session 4 (knowledge about milk and dairy products and bone health) and $6.9 \%$ insession 5 (knowledge about physical exercise). The percentages of students who scored fair after application of intervention were increased to $35.2 \%, 46.6 \%, 29.1 \%$, $17.0 \%$ and $55.1 \%$ in sessions 1 to 5 respectively. Only Three percent of studied sample scored fair in all sessions combined pre intervention and the percentage increased to $50.6 \%$ after application of the intervention. Similar patterns in percentages of those who scored poor, fair and good were found in both male and female students in sessions 1 to 5 and all sessions combined respectively (see table 2). Table 2 also showed a statistical increase in mean score knowledge post intervention compared to pre intervention in the 5 previous sessions (9.4 vs 4.6 in session
$1 ; 7.5$ vs 3.5 in session $2 ; 3.0$ vs 1.7 in session $3 ; 3.7$ vs 1.3 in session 4 and 4.4 vs 2.4 in session 5) with $p$ value less than 0.0001 in all. Overall mean score of knowledge obtained in the five sessions combined was increased from 13.5 pre intervention to 28.1 after giving the nutrition intervention program and the increase was a statistically significant $(\mathrm{p}$ value $<0.0001)$. There was a statistical difference between male and female students pre intervention in session 2 (3.3 vs 3.8, $\mathrm{p}$ value $=0.05)$; session 3 (1.4 vs $1.9, \mathrm{p}$ value $=0.002)$, session 4 (1.5 vs $1.1, \mathrm{p}$ value $=0.004)$ and all sessions combined (12.9 vs 14.3, p value $=0.02)$. Post intervention there was a significant difference between male and female students only in session 4 (3.5 vs 3.4, p value $=0.006)$ and in session 5 (4.2 vs 4.8, p value $=0.002$ ). Table 2 also showed that there was a significant increase in mean score of knowledge post intervention compared to pre intervention in each session and in all sessions combined in both male and female students.

Table 3 showed overall total score of knowledge of middle school students before and after intervention based on gender and location of school. There was a significant increase in overall scores of nutrition knowledge after intervention in male and female students irrespective to location of school and $\mathrm{P}$ was less than 0.0001. Also in figure 2 the change in mean nutrition knowledge score before and after intervention is demonestrated.

\section{Discussion}

Adolescence is the stage of life between ages of 11 and 21 years ${ }^{(14)}$. During this time, significant changes occur, which prepares a child for adulthood. The rapid growth and development during this 
stage increases energy and nutrient requirements ${ }^{(15-17)}$.

Egypt is undergoing rapid nutritional transition driven by aggressive advertising, low cost and easy availability of high-saturated-fat snacks, refined carbohydrates and sweetened carbonated beverages. There is an increased inclination to replace traditional meals with energy-dense imbalanced foods (18). Such dietary patterns with inadequate physical activity trigger the onset of fat deposition (19) and lead to early metabolic derangements such as the metabolic syndrome and type 2 diabetes mellitus ${ }^{(18)}$.

This study highlights marked gaps in nutrition related knowledge of elementary schools children chosen from selected govermental schools of two governorates in Egypt. High prevalence of overweight and obesity was noticed in both male and female students. Findings of this study also showed that after application of nutrition education intervention, a significant improvement in nutrition knowledge irrespective to gender or location of school.

The current study showed that only 3.3\% of the studied sample have fair knowledge $(50-75 \%$ of answers were correct)(Table 2). However, the percentage of students (aged 12.5-17.49 years old) who have fair knowledge in a study conducted in nine European countries were 15 times much higher $(60 \%)$ than the percentage reported in the current study ${ }^{(20)}$ and in another study included urban Asian Indian children from govermental schools (aged 12-14 years old), the percentage was four times much higher ${ }^{(9)}$. The low literacy related to nutrition in the current study may have a bad repercussion in their adulthood translated on bad choices of food, energy imbalance and consequently failure in weight management. However, this low literacy may not generally represent the whole school children in Egypt, as the current study was purposive sample and include only selected govermental schools from two governorates in Egypt. Interstingly, mean score of total knowledge was slightly higher in female students (14.3) compared to male students (12.9). Smilarly, studies from several countries in Europe, USA and Malysia found that female studnets have a higher knowledge score than their male counterparts ${ }^{(20-22)}$.

The prevelances of overweight and obesity among the studied sample was $17.0 \%$ and $10.9 \%$ respectively.Results from Global School based Student Health Survey (GSHS) conducted in seven African Countries with Egypt one of the studied countries between 20062010 on adolescents school children aged 13-17 years old indicated that the prevalence of overweight ranged from $8.7 \%$ to $31.4 \%$ and obesity ranged from $0.6 \%$ to $9.3 \%$ with Egypt the highest prevalence in overweight $(31.4 \%)$ and obesity $(9.3 \%)^{(23)}$. Although the current study showed that the prevalence of obesity among Egyptian adolescents reported in this study $(10.9 \%)$ was close to that reported in GSHS survey, however, the prevalence of overweight was nearly half $(17.0 \%)$ of that of overweight in Egypt reported in GSHS survey. But the prevalence of overweight reported in the current study still higher that those reported by the 5 other African countries which ranged between $8.7 \%-18.8 \%$. However, The prevalence of obesity reported in the current study was lower than that reported in Data from National Health and Nutrition Examination Survey (NHANES) (17.8\% 
$-20.5 \%$ of U.S. adolescents aged 12-19 years are obese; $18.2 \%$ to 20.3 in boys and $17.3 \%$ to $20.7 \%$ in girls) from the 2007-2012. Higher prevalence of overweight and obesity among adolescents in the current study could be explained partly by changing dietary patterns associated with the rapid urbanization (24) and the physical inactivity.

The current study also revealed a higher prevalence of obesity in girls compared to boys. Similarly, Data from GSHS showed the same patterns in some countries however, in others there were no difference between boys and girls ${ }^{(23)}$. Based on the above findings of the situtation analysis conducted before the application of the intervention, the studied school children required an intervention educational program in order to improve their nutrtion knowledge and hopefully this will be reflected on their practice in the future. Earlier in 1998, WHO ${ }^{(6)}$ argued that schools are vitally important setting to provide nutrition intervention programs. Our study and others from multiple countries ${ }^{(7-9,11,13,25)}$ make a convincing case through the significant improvement in learning outcomes of the targeted school children.

The period of implementation of the intervention program has a significant effects on the outcome of the intervention. Several studies have shown that an implementation period of 4 to 13 weeks was sufficient to improve the nutrion knowledge of students, but may produce inconclusive results regarding practice ${ }^{(10,11,26)}$. Our study have shown that intervention of 5 weeks duration produced a significant improvements in the overall knowledge of the participants.
A nutrition intervention programs targeting adolescents produced succesful results when they have multiple pillars to focus on including behavioral, individual, enviromental, and theoritical content (duration and intensity) appropriate to the age of audience ${ }^{(27,28)}$. Moreover, these programs focucing on younger adolescents should include strategies such as self assessment, modeling and basic discussions about media and social influences. Several studies have shown that using different teaching and learning strategies can enhance the learning outcomes of school children ${ }^{(7,9-11,13)}$. For instance besides the classical clasroom based teaching, other activities such as group discussion on nutrition topics, demonstrations, nutriton contests and other methods has enhanced learning among students. Similarly in our study, different learning and teaching strategies have been used such as small group discussions, group work, demonstrations, nutrition exhibitions, art educational drawing helped in the success of the intervention program (a significant increase in the overall score of knowledge from 13.5 to 28.1) . Moreover, an educational bookelets were distributed to participants to enhance the retention of knowledge.

The results of this study support the concept that school nutrition intervention programs can have a great impact on knowledge and behavior of middle school students especially if variable methods of teaching and learning were applied. However, does these changes will be sustained in the longer term the current study can not answer this question therefore future studies need to address this issue. The results of this study can not be generalized to other middle schools in Egypt due to the purposiveness charectistics of sample. A

$\begin{array}{llll}\text { Vol. } 33 & \text { No. } 4 & \text { October } & 2015\end{array}$


self reported tool was used in the study so there may be a recall bias that may affect the internal validity of the study. Additionally, no comparison group and no significant gap between the intervention and post test. Despite those limitations, this study is the first published as far as we know to implement and evaluate a school nutrition intervention program in Egypt.

In conclusion, this study has shown that a school nutrition intervention program could have positive effects on adolescent's school children. In addition, the utilization of different teaching and learning strategies such as group discussion on nutrition topics, demonstrations, nutrition contests, games and other methods may enhance the learning process of the students and increase their awarness towards healthy nutritional behavior. As reported before, nutrition is a complex issue where multiple factors not inclusive such as, political commitment, commmunity commitment and environmental factors at school can intervene in developing or adopting healthy nutritional behavior among adolescents. Therefore, we recommend the intercollaborative approach /between different minsteries such as education, health, food and agriculture to set polices and guidelines that support the healthy nutritional behavior among school children. Also school enviroment need to be supportive to the adoption of healthy behavior by providing education about nutrition as a specific subject or as a part of other subject areas such as science, home economic, controling the food choices at school and at outside vendor that may be present on or near school property, feeding programmes family involvement and food handling procedures. The curent program can be applied in other schools setting, after providing a training course to the the school teachers and over a longer period with frequent evaluation and make nessary changes. Or can be subjected to process of implementation and evaluation and replanning in other school settings.

\section{References}

1) Galal O.M. and Hulett J. (2005). Obesity among schoolchildren in developing countries.Food and Nutrition Bullettin, 26(2 Suppl 2):S261-266.

2) El-Zanaty F. and Way A (2009). Egypt Demographic and Health Survey 2008. Cairo, Egypt: Ministry of Health, El-Zanaty and Associates, and Macro International.

3) WHO, (2004). Fight childhood obesity to help prevent diabetes, say WHO \& IDF Available at http://www.who.int/mediacentre/new s/releases/2004/pr81/en/

4) CDC (2014). Childhood obesity facts-Adolescents school health. Available at http://www.cdc.gov/healthyyouth/ob esity/facts.htm

5) Pietsch (2009). Growing Healthy Minds and Bodies, A Look at Nutrition Innovation in Schools. Nutritional file for health educators. Page: 1-8. Available at http://www.moreaboutmilk.com/med ia/nutrition_file_newsletters/aug2009 nffhefinal.pdf.

6) WHO, (1998). WHO information series on school health. Document 4. Healthy nutrition: An essential element of a health promotion. Geneva: WHO. Available at http://www.who.int/hpr 
7) Mait S., Chatterjee K., Ali K. M., Debasis D., Bera T. K., Jana K. and Ghosh D. (2011). The Impact of Nutritional Awareness Package (NAP) on Secondary School Students for the Improvement of Knowledge, Attitudes and Practices (KAP) at Rural Areas of West Medinipur, West Bengal. Asian Journal of Medical Sciences 2, 8792.

8) Roszanadia R. and Norazmir M.N. (2011). Knowledge, attitude and practice on healthy eating among special needs boarding school students. International Journal of Dairy Science, 10 (3923), 1-9.

9) Shah P. , Misra A., Gupta N., Hazra D.K., Gupta R., Seth P. and et al. (2010). Improvement in nutrition-related knowledge and behaviour of urban Asian Indian school children: findings from the 'Medical education for children/Adolescents for Realistic prevention of obesity and diabetes and for healthy ageing' (MARG) intervention study. British Journal of Nutrition, 104, 427-436.

10) Fahlman M. M., Dake J.A., Mccaughtry N. and Martin J. (2008). A pilot study to examine the effects of a nutrition intervention on nutrition knowledge, behaviors, and efficacy expectations in middle school children. Journal of School Health, 78 (4), 216-222.

11) Shariff Z. M., Bukhari S. S., Othman N., Hashim N., Ismail M., Jamil Z. and et al. (2008). Nutrition education intervention improves nutrition knowledge,attitude and practices of primary school children: a pilot study. International Electronic Journal of Health Education, 11, 119-132.
12) Ruzita A.T., Wan Azdie M.A.B. and Ismail M.N. (2007). The Effectiveness of Nutrition Education Programme for Primary School Children. Malaysian Journal of Nutrition, 13(1), 45-54.

13) Abdel Gawwad E. S., Fetohy E. M., Fiala L., Al Orf S. M and Al Saif M. (2006). Impact evaluation of nutrition education intervention for an elementary school in riyadh city. The Journal of Egyptian Public Health Association, 81(1-2), 75-97.

14) Stang J (2011). Adolescent nutrition. In Nutrition Through the Life Cycle, J. E. Brown, Ed., Cengage Learning, Wadsworth, Ohio, USA, 4th edition, pp. 356384.

15) Oliveira M. N. G., Almada Cezar E. H., and Soares E. D. A. (2000). Comparison of the anthropometric assessment of adolescents of privileged and unprivileged social and economic levels. Nutrition Research, 20(10), 1423-1436.

16) Tur J. A., Puig M. S., Benito E., and Pons A.( 2004). Associations between sociodemographic and lifestyle factors and dietary quality among adolescents in Palma de Mallorca. Nutrition, 20(6), 502-508.

17) Przysławski J., Stelmach M., Grygiel-Górniak B., Mardas M., and Walkowiak J. (2011). Dietary habits and nutritional status of female adolescents from the great Poland region. Polish Journal of Food and Nutrition Sciences, 61(1), 73-78.

18) Lu, J. P., Dai, X. L., Yu, L. L. and Zhang, Y. A. (2001). Impact of health education on the improvement 
on anemia in students. China Journal of School Health, 22, 315-316.

19) EGYPT Nutrition Landscape Analysis Report (ENLA) (2012)

20) Sichert-Hellert W., Beghin L., De Henauw S., Grammatikaki E., Hallstro L., Manios Y. and et al. (2011). Nutritional knowledge in European adolescents: results from the Helena (Healthy Lifestyle in Europe by Nutrition in Adolescence) study. Public Health Nutrition, 14(12), 2083-2091.

21) Farah Wahida Z., Mohd Nasir M.T. and Hazizi A.S. (2011). Physical Activity, Eating Behaviour and Body Image Perception among Young Adolescents Physical Activity, Eating Behaviour and Body Image Perception among Young Adolescents in Kuantan, Pahang,Malaysia. Malaysian Journal of Nutrition, 17(3), $325-336$.

22) Pirouznia M. (2001). The influence of nutrition knowledge on eating behavior - the role of grade level. Nutrition \& Food Science, 31 (2), $62-67$.

23) Manyanga T., El-Sayed H., Doku D.T. and Randall J.R. (2014). The prevalence of underweight, overweight,obesity and associated risk factors among school-going adolescents in seven African
Countries. BMC Public Health, 14(887), 1-11.

24) Galal O.M .(2002). The nutrition transition in Egypt: obesity, undernutrition and the food consumption context. Public Health Nutrition: 5(1A), 141-148.

25) Saksvig B.I.,Gittelsohn J., Harris S.B., Hanley A. J.G., Valente T.W. and Bernard Z. (2005). A Pilot School-Based Healthy Eating and Physical Activity Intervention Improves Diet, Food Knowledge, and Self-Efficacy for Native Canadian Children 1,2. Journal of Nutrition, 135, 2392-2398.

26) Harrabi I., Maatoug J., Gaha M., Kebaili R., Gaha R. and Ghannem H. (2010). Schoolbased intervention to propmote healthy lifestyles in Sousse, Tunisia. Indian Journal of Community Medicine, 35(1), 94-99.

27) Hoelscher D.M., Evans A., Parcel G.S., Kelder S.H. (2002). Designing effective nutrition interventions for adolescents. Supplement to The American Dietetic Association, 102(3), S52-S63.

28) PeÂrez-Rodrigo C. and Aranceta J. (2001). School-based nutrition education: lessons learned and new perspectives. Public Health Nutrition, 4(1A), 131-139. 
Table 1: Total nutrition knowledge score before intervention by gender and school type

\begin{tabular}{|c|c|c|c|}
\hline Variable & Total number & $\begin{array}{c}\text { Total knowledge score } \\
(\text { Mean } \pm \text { SD) }\end{array}$ & $\mathrm{P}$ value \\
\hline Gender & $\mathrm{N}=247$ & & \multirow[t]{3}{*}{$0.02 *$} \\
\hline Male & 148 & $13.0 \pm 4.4$ & \\
\hline Female & 99 & $14.3 \pm 3.9$ & \\
\hline School type & & & \multirow[t]{5}{*}{$0.004 * *$} \\
\hline Male & $\mathrm{N}=148$ & & \\
\hline Urban (Cairo) & 80 & $13.6 \pm 4.6$ & \\
\hline Semi-urban (Giza) & 33 & $13.8 \pm 3.4$ & \\
\hline Rural (Giza) & 35 & $10.9 \pm 3.9$ & \\
\hline Female & $\mathrm{N}=99$ & & \multirow[t]{4}{*}{$0.002 * *$} \\
\hline Semi-urban (Cairo) & 40 & $15.9 \pm 3.4$ & \\
\hline Semi-urban (Giza) & 22 & $13.4 \pm 2.7$ & \\
\hline Rural (Giza) & 37 & $13.1 \pm 4.4$ & \\
\hline All sample & $\mathrm{N}=247$ & $13.5 \pm 4.2(33 \%)$ & \\
\hline
\end{tabular}

"student's t test

**Analysis of variance (ANOVA) test

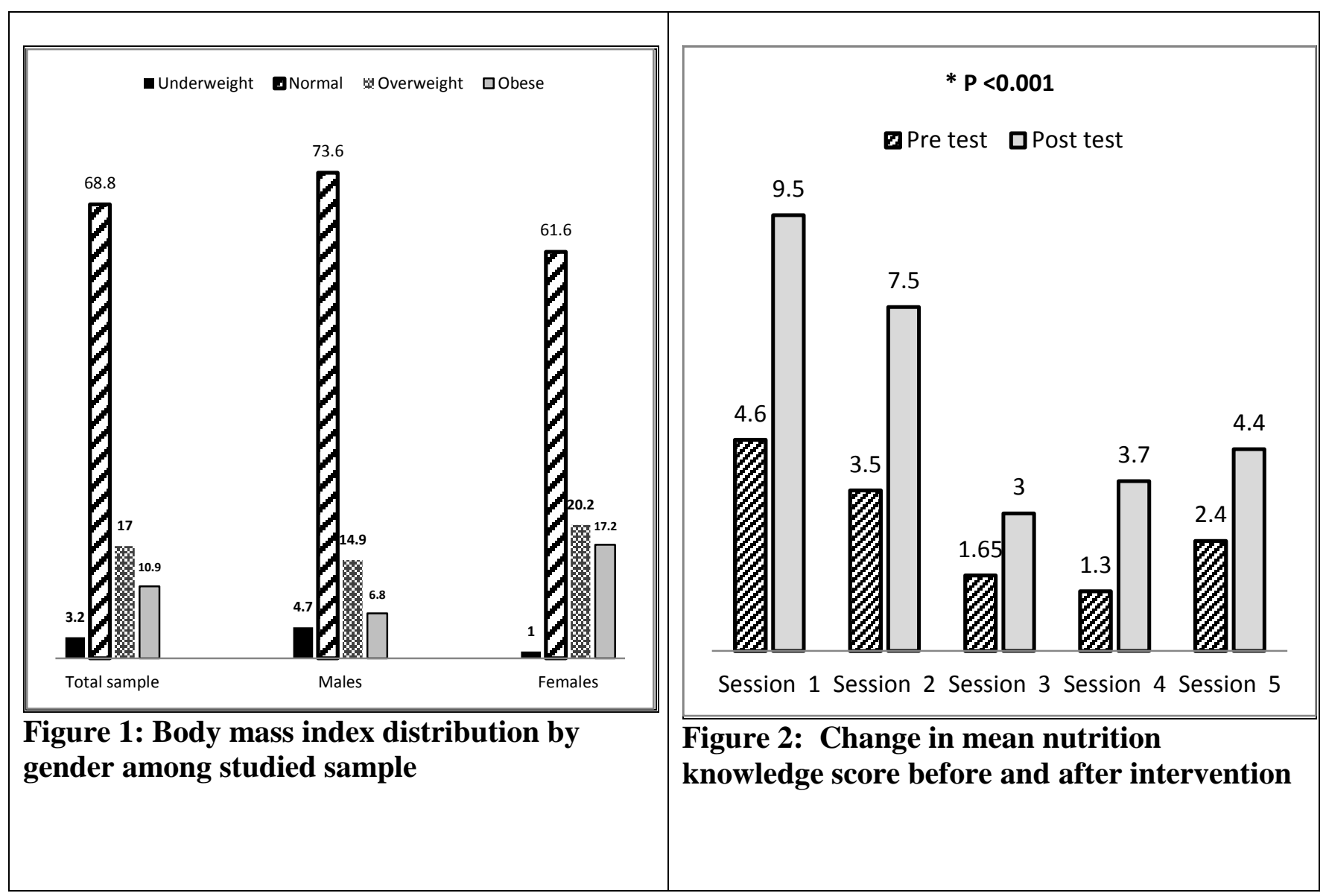


Table 2: Nutrition knowledge score of preparatory school students before and after intervention by gender

\begin{tabular}{|c|c|c|c|c|c|c|}
\hline \multirow{2}{*}{$\begin{array}{l}\text { Score of } \\
\text { knowledge } \\
\text { (Know) }\end{array}$} & \multicolumn{2}{|c|}{$\begin{array}{c}\text { Total sample } \\
(\mathrm{N}=247)\end{array}$} & \multicolumn{2}{|c|}{$\begin{array}{l}\text { Male students } \\
\quad(\mathrm{N}=148)\end{array}$} & \multicolumn{2}{|c|}{$\begin{array}{c}\text { Female students } \\
(\mathrm{N}=99)\end{array}$} \\
\hline & $\begin{array}{c}\text { Pre } \\
\text { intervention }\end{array}$ & $\begin{array}{c}\text { Post } \\
\text { intervention }\end{array}$ & $\begin{array}{c}\text { Pre } \\
\text { intervention }\end{array}$ & $\begin{array}{c}\text { Post } \\
\text { intervention }\end{array}$ & $\begin{array}{c}\text { Pre } \\
\text { intervention }\end{array}$ & $\begin{array}{c}\text { Post } \\
\text { intervention }\end{array}$ \\
\hline \multicolumn{7}{|c|}{ Session 1: Health benefits of Essential nutrients } \\
\hline Poor & $213(86.2)$ & $29(11.7)$ & $131(88.5)$ & $21(14.2)$ & $82(82.8)$ & $8(8.1)$ \\
\hline Fair & $34(13.8)$ & $87(35.2)$ & $17(11.5)$ & $44(29.7)$ & $17(17.2)$ & $43(43.4)$ \\
\hline Good & - & $131(53.1)$ & & $83(56.1)$ & & $48(48.5)$ \\
\hline $\begin{array}{l}\text { Mean score of } \\
\text { know } \pm \text { SD }\end{array}$ & $4.6 \pm 1.8$ & $\underset{\mathrm{P} 1}{9.4 \pm 2.4}$ & $4.5 \pm 1.7$ & $\underset{\mathrm{P} 1}{9.6 \pm 2.6}$ & $\begin{array}{l}4.8 \pm 1.9 \\
\mathrm{P} 2, \mathrm{NS}\end{array}$ & $\begin{array}{l}9.3 \pm 2.1 \\
\text { P1 P3,NS }\end{array}$ \\
\hline \multicolumn{7}{|c|}{ Session 2: Food groups in food pyramid and serving size } \\
\hline Poor & $206(83.4)$ & $44(17.8)$ & $121(81.8)$ & $25(16.9)$ & $85(85.9)$ & $19(19.2)$ \\
\hline Fair & $41(16.6)$ & $115(46.6)$ & $27(18.2)$ & $73(49.3)$ & $14(14.1)$ & $42(42.4)$ \\
\hline Good & - & $88(35.6)$ & & $50(33.8)$ & & $38(38.4)$ \\
\hline $\begin{array}{c}\text { Mean score of } \\
\text { know } \pm \text { SD }\end{array}$ & $3.5 \pm 2.1$ & $7.5 \pm 2.2$ & $3.3 \pm 2.3$ & $\underset{\mathrm{P} 1}{7.4 \pm 2.1}$ & $3.8 \pm 1.7$ & $\begin{array}{c}7.7 \pm 2.3 \\
\text { P1 P3NS }\end{array}$ \\
\hline \multicolumn{7}{|c|}{ Session 3: Dietary guidelines } \\
\hline Poor & $172(69.6)$ & $64(25.9)$ & $112(75.5)$ & $38(25.7)$ & $60(60.6)$ & $26(26.2)$ \\
\hline Fair & $45(18.2)$ & $72(29.2)$ & $25(16.9)$ & $44(29.7)$ & $20(20.2)$ & $28(28.3)$ \\
\hline Good & $30(12.2)$ & $111(44.9)$ & $11(7.6)$ & $66(44.6)$ & $19(19.2)$ & $45(45.5)$ \\
\hline $\begin{array}{l}\text { Mean score of } \\
\text { know } \pm \text { SD }\end{array}$ & $1.7 \pm 1.4$ & $3.0 \pm 1.1$ & $1.4 \pm 1.3$ & $3.0 \pm 1.1$ & $\underset{\mathrm{P} 2^{* *}}{1.9 \pm 1.4}$ & $\begin{array}{l}3.0 \pm 1.2 \\
\mathrm{P} 1, \mathrm{P} 3, \mathrm{NS}\end{array}$ \\
\hline \multicolumn{7}{|c|}{ Session 4: Milk, Dairy products and Bone health } \\
\hline Poor & $207(83.8)$ & $48(19.4)$ & $115(77.7)$ & $32(21.6)$ & $92(92.9)$ & $16(16.2)$ \\
\hline Fair & $23(9.3)$ & $42(17.0)$ & $17(11.5)$ & $28(18.9)$ & $6(6.1)$ & $14(14.1)$ \\
\hline Good & $17(6.9)$ & $157(63.6)$ & $16(10.8)$ & $88(59.5)$ & $1(1.0)$ & $69(69.7)$ \\
\hline $\begin{array}{l}\text { Mean score of } \\
\text { know } \pm \text { SD }\end{array}$ & $1.3 \pm 1.2$ & $3.7 \pm 1.3^{\mathrm{Pl}}$ & $1.5 \pm 1.4$ & $3.5 \pm 1.3^{\mathrm{Pl}}$ & $1.1 \pm 0.9^{\mathrm{P} 2^{* *}}$ & $3.4 \pm 1.3^{\mathrm{P} 1}$ \\
\hline \multicolumn{7}{|c|}{ Session 5: Physical activity } \\
\hline Poor & $230(93.1)$ & $111(44.9)$ & $140(94.6)$ & $78(52.7)$ & $90(90.9)$ & $33(33.3)$ \\
\hline Fair & $17(6.9)$ & $136(55.1)$ & $8(5.4)$ & $70(47.3)$ & $9(9.1)$ & $66(66.7)$ \\
\hline $\begin{array}{l}\text { Mean score of } \\
\text { know } \pm \text { SD }\end{array}$ & $2.4 \pm 1.6$ & $4.4 \pm 1.5^{\mathrm{PI}}$ & $2.3 \pm 1.6$ & $4.2 \pm 1.6^{\mathrm{PI}}$ & $\begin{array}{c}2.6 \pm 1.5 \\
P 3=0.14\end{array}$ & $\begin{array}{c}4.8 \pm 1.3^{\mathrm{PI}} \\
\mathrm{P} 4=0.002\end{array}$ \\
\hline \multicolumn{7}{|c|}{ All sessions combined } \\
\hline Poor & $\begin{array}{l}237 \\
(96.7 \%)\end{array}$ & $30(12.2)$ & $143(96.6)$ & $18(12.2)$ & $94(94.9)$ & $12(12.2)$ \\
\hline Fair & $10(3.3 \%)$ & $125(50.6)$ & $5(3.4)$ & $81(54.7)$ & $5(5.1)$ & $44(44.4)$ \\
\hline Good & - & $92(37.2)$ & - & $49(33.1)$ & - & $43(43.4)$ \\
\hline $\begin{array}{c}\text { Mean score of } \\
\text { know } \pm \text { SD }\end{array}$ & $13.5 \pm 4.2$ & $28.1 \pm 6.3^{\mathrm{P} 1}$ & $12.9 \pm 4.4$ & $27.7 \pm 6.3^{\mathrm{PI}}$ & $\begin{array}{l}14.3 \pm 3.9 \\
\mathrm{P} 3=0.02\end{array}$ & $\begin{array}{l}28.8 \pm 6.2^{\mathrm{Pl},} \\
\mathrm{P} 4=0.18\end{array}$ \\
\hline \multicolumn{7}{|c|}{$\begin{array}{l}\text { Scores; good, score }>75 \% \text {; fair, score } 50 \%-75 \% \text {; poor, score }<50 \% \text { of maximum } \\
{ }^{\mathrm{P} 1} \text { Comparison between preintervention and post intervention using paired samples } \mathrm{T} \text { test, All } \mathrm{p} 1 \text { was } \\
<0.0001 \text {. } \\
{ }^{\mathrm{P} 2} \text { Comparison between pre intervention in male and preintervention in female using independent samples t } \\
\text { test. } \\
{ }^{\mathrm{P} 3} \text { Comparison between post intervention in male and post intervention in female using independent } \\
\text { samples T test. } \\
\mathrm{NS}=\text { not significant, }{ }^{*} \mathrm{p} \leq 0.05,{ }^{* *} \mathrm{P} \leq 0.01\end{array}$} \\
\hline The Egyptia & urnal of Co & near & Vol. & No. 4 & October & 2015 \\
\hline
\end{tabular}


Table 3: Overall total nutrition knowledge score (all sessions combined)of preparatory school students before and after intervention based on gender and location of school.

\begin{tabular}{|l|c|c|c|c|}
\hline & $\begin{array}{c}\text { Urban } \\
\text { Cairo }\end{array}$ & $\begin{array}{c}\text { Semiurban } \\
\text { Cairo }\end{array}$ & $\begin{array}{c}\text { Semiurban } \\
\text { Giza }\end{array}$ & $\begin{array}{c}\text { Rural } \\
\text { Giza }\end{array}$ \\
\hline Males & $\mathrm{N}=80$ & & $\mathrm{~N}=33$ & $\mathrm{~N}=35$ \\
\hline preintervention & $13.6 \pm 4.6$ & & $13.7 \pm 3.4$ & $10.9 \pm 3.9$ \\
\hline Post intervention & $27.4 \pm 6.6$ & & $29.1 \pm 6.5$ & $26.9 \pm 5.1$ \\
\hline P value & $<\mathbf{0 . 0 0 0 1}$ & & $<\mathbf{0 . 0 0 0 1}$ & $<\mathbf{0 . 0 0 0 1}$ \\
\hline Females & & $\mathrm{N}=40$ & $\mathrm{~N}=22$ & $\mathrm{~N}=37$ \\
\hline preintervention & & $15.9 \pm 3.4$ & $13.4 \pm 2.7$ & $13.05 \pm 4.4$ \\
\hline Post intervention & & $27.5 \pm 5.5$ & $29.6 \pm 7.1$ & $29.7 \pm 6.4$ \\
\hline P value $^{*}$ & & $<\mathbf{0 . 0 0 0 1}$ & $<\mathbf{0 . 0 0 0 1}$ & $<\mathbf{0 . 0 0 0 1}$ \\
\hline
\end{tabular}

"Paired t test 